\title{
Core-shell like structured barium zirconium titanate-barium calcium titanate-poly(methyl methacrylate) nanocomposites for dielectric energy storage capacitors
}

\author{
Venkata S. Puli ${ }^{1,3^{*}}$, Muhammad Ejaz ${ }^{2}$, Ravinder Elupula ${ }^{2}$, Manish Kothakonda ${ }^{1}$, Shiva \\ Adireddy $^{1}$, Ram S. Katiyar ${ }^{3}$, Scott M. Grayson ${ }^{2}$, Douglas B. Chrisey ${ }^{1}$ \\ ${ }^{1}$ Department of Physics and Engineering Physics, Tulane University, New Orleans- LA 70118, \\ USA \\ ${ }^{2}$ Department of Chemistry, Tulane University, New Orleans- LA 70118, USA \\ ${ }^{3}$ Department of Physics, University of Puerto Rico, San Juan-00936, PR, USA
}

\begin{abstract}
Core-shell like structured barium zirconium titanate-barium calcium titanate-poly(methyl methacrylate) $\left[\left(\mathrm{Ba}_{0.94} \mathrm{Ca}_{0.06}\right)\left(\mathrm{Zr}_{0.16} \mathrm{Ti}_{0.84}\right) \mathrm{O}_{3}\right.$-PMMA] nanocomposites were prepared by surfaceinitiated atom transfer radical polymerization (SI-ATRP) of methyl methacrylate (MMA) from the surface of BZT-BCT nanoparticles. X-ray diffraction patterns of pure polymer and BZT-BCT nanoparticles revealed their amorphous and polycrystalline natures respectively. Fourier transform infrared spectroscopy confirmed the grafting of the PMMA shell on the surface of the BZT-BCT nanoparticles cores. Transmission electron microscopy (TEM) results revealed that BZT-BCT nanoparticles were covered by a very thin layer of PMMA forming a core-shell like structure and thermogravimetric analysis results showed that the grafted BZT-BCT-PMMA nanoparticles consist of $\sim 80.1 \%$ PMMA by weight. Polymer grafted BZT-BCT nanocomposite thick films $(\sim 10 \mu \mathrm{m})$ have shown an improved dielectric constant ( $\varepsilon \sim 56)$, a high breakdown field strength $(\sim 3 \mathrm{MV} / \mathrm{cm})$ and high-energy storage density $\sim 22.5 \mathrm{~J} / \mathrm{cm}^{3}$. The improved electrical properties of core-shell like structured BZT-BCT-PMMA nanocomposites were attributed to improved nanoparticle dispersion and enhanced interfacial polarization due to the covalent linkage between polymer and nanoparticle interface. Mechanically stable and homogeneous composite films were obtained using the surface grafted BZT-BCT ceramic nanoparticles.
\end{abstract}

Keywords: Atom transfer radical polymerization, dielectrics, energy storage, poly(methyl methacrylate), nanocomposites, capacitors 
Corresponding Author: E-mail: (*) pvsri123@gmail.com, Tel: +1- 239-537-4964

\section{Introduction}

Ceramic materials with high dielectric permittivity and low dielectric losses have attracted attention because of their important applications in the electrical and electronic industries. In particular, perovskite based ceramic materials such as barium titanate, $\mathrm{BaTiO}_{3}$ (BTO), and lead zirconium titanate, $\mathrm{PbZrTiO}_{3}$, (PZT) etc., are widely used in capacitors due to their excellent dielectric properties. For next-generation capacitive electrical energy storage applications, materials with high dielectric permittivity, low dielectric loss, and high dielectric breakdown strength (DBS) are essential for high gravimetric energy storage capacity. High-energy density storage capacitors, by definition, store more energy per unit volume than common capacitors. These capacitors play a key role in stationary power systems, mobile electronic devices, hybrid electric vehicles, and pulsed power applications due to their reliability and fast charge-discharge characteristics $^{1}$. Conventional ceramics have excellent dielectric properties (high dielectric permittivity and low dielectric loss). And these high dielectric constant dielectric materials are widely used in energy storage devices applications. However, their low DBS limits the energy storage density and performance of the capacitor, which is detrimental in meeting the high energy density capacitor functional requirements ${ }^{2}$. Polymeric dielectric materials on the other hand, have some advantages over the traditional electroactive ceramics, e.g., low cost, high mechanical elasticity, high electrical breakdown strength, ease of processing in large areas/volumes, and self-healing ability ${ }^{3}$. However, most dielectric polymers possess relatively low dielectric constants ranging from 2 to $12^{4}$.

An effective alternative approach is to fabricate flexible polymer composites by combining ceramic nanoparticles and polymers to leverage their complementary properties. Over the past few years, many researchers worldwide have focused on developing polymer-based nanocomposites filled with high dielectric permittivity ceramic nanoparticles, in order to combine the high dielectric permittivity of ceramics and the high breakdown strength of polymers. However, introducing ceramic nanoparticles into a polymer matrix by a simple solvent mixing often causes a drastic decrease in dielectric breakdown strength (DBS) which offsets the advantages offered by the improved dielectric permittivity ${ }^{5}$. The decrease of DBS in 
polymer/nanoparticle composites when compared with pure polymer's DBS is attributed to the agglomeration of ceramic nanoparticles, and generation of pores or voids that lead to charge accumulation and subsequent dielectric breakdown within the composite ${ }^{5}$.

Accumulated energy storage density or volumetric energy density $\left(E_{d^{-}}\right.$in $\left.J / \mathrm{cm}^{3}\right)$ in linear dielectrics is determined by dielectric constant $(\varepsilon)$, permittivity of free space $\left(\varepsilon_{0}\right)$ and breakdown strength $\left(\mathrm{E}_{\mathrm{b}}\right)$. $\mathrm{E}_{\mathrm{d}}$ has a linear relationship with dielectric constant $(\varepsilon)$ and quadratic dependence on the electric field $\left(E_{b}\right)$ as shown in the following equation (1):

$$
E_{d}=\int_{0}^{P \max } E_{b} d P=\frac{1}{2} \in_{0} \in E_{b}^{2}
$$

To obtain higher energy densities both high dielectric permittivity and high breakdown strength are required. However, a two-fold increase in the breakdown strength can increase the overall energy density by four-fold. The quadratic dependence has inspired numerous efforts in the past few years to combine polymers exhibiting high dielectric breakdown strength with ceramic nanoparticles of high dielectric constant to improve the electrical energy storage density ${ }^{6}$. Volumetric energy storage density is the key factor for a dielectric capacitor; it denotes the amount of energy stored in the device and also determines the performance of the capacitor.

When compared to micron-sized ceramic particles, nanoparticles have shown improved dielectric properties. The enhanced dielectric properties of nano-sized particles have been attributed to reduced interfacial polarization and lower nanoparticle agglomeration ${ }^{7}$. Also, adding nano-sized $\mathrm{TiO}_{2}$ as an additive as opposed to micron-sized $\mathrm{TiO}_{2}$ has shown to improve dielectric properties of ceramic nanoparticles. The incorporation of nanoparticles results in reduced porosity and leads to a random close-packed microstructure in the final composite ${ }^{8}$. Furthermore, ceramic-polymer nanocomposites offer several very important processing advantages including mechanical flexibility and the ability to be easily molded into customized shapes; both features make them attractive materials for use in low cost, compact electrical and electronics devices.

There are various types of mixing processes that were explored to make flexible polymerceramic nanocomposites materials for electrical energy storage applications, which include 
conventional mixing and covalently grafting of polymers from ceramic particles. In conventional mixing process, the homogeneous dispersion of nanoparticles in polymer matrices is achieved by tuning the surface energies of nanoparticles ${ }^{9}$. Surface hydroxylation of nanoparticles is another approach that was utilized to make nanoparticles disperse better in the polymer matrix ${ }^{5}$. Many other research efforts have also been reported for improving nanoparticles dispersion, such as surface modification of nanoparticles by organic molecules such as silanes ${ }^{10}$, phosphonic acid $^{11}$, and ethylene diamine ${ }^{12}$; surface initiated in-situ polymerization techniques ${ }^{13}$; and nanocomposite hybrid filler mixtures ${ }^{9 b, 14}$. To improve the interfacial compatibility and enhance the dielectric properties, surface modification of fillers by covalent polymer grafting is the most effective way to achieve homogenous composites ${ }^{15}$. Using a surface grafting technique, polymer chains can be chemically grown from the surface of ceramic nanoparticles, which in turn strengthens the interactions between inorganic ceramic fillers and the polymer matrix, resulting in better dispersion of the ceramic filler and ultimately decreases the interfacial defects. With the increased scope of controlled radical polymerization (CRP) techniques, the design and synthesis of high permittivity core-shell structured hybrid nanoparticles, in which ceramic cores are covalently grafted with polymer chains, has become an appealing route to resolve the interfacial incompatibility between fillers and matrix and can yield improved composites for high energy storage capacitors ${ }^{15-16}$.

Herein, we report the synthesis, physical characterization, dielectric evaluation, and energy storage properties of core-shell structured PMMA grafted BZT-BCT nanocomposite prepared by surface-initiated atom transfer radical polymerization (SI-ATRP) of MMA monomer from the surface of $\left[\left(\mathrm{Ba}_{0.94} \mathrm{Ca}_{0.06}\right)\left(\mathrm{Zr}_{0.16} \mathrm{Ti}_{0.84}\right) \mathrm{O}_{3}\right](\mathrm{BZT}-\mathrm{BCT})$ nanoparticles.

\section{Experimental details}

\section{Materials}

Methyl methacrylate (MMA, 99\%, Aldrich) was purified by passing through basic alumina. Copper (I) bromide (CuBr, 98\%, Sigma-Aldrich) was purified by successively washing with glacial acetic acid, ethanol, and ethyl ether followed by drying under vacuum at room temperature. 4,4'-Dinonyl-2,2'-dipyridine (DNDP, 97\%, Aldrich), $p$-toluene sulfonyl chloride (PTSC, 97\%, Sigma Aldrich), 2-(4-chlorosulfonylphenyl) ethyl trichlorosilane (CTC, 50\% in 
methylene chloride, Gelest), and other reagents were used as received unless otherwise mentioned.

Perovskite crystalline structured BZT-BCT nanoparticles (<100 nm) were synthesized using sol-gel synthesis technique ${ }^{17}$. The dielectric, ferroelectric and energy storage properties of BZTBCT ceramic nanoparticles were reported elsewhere ${ }^{17}$. Functionalization of BZT-BCT nanoparticles by grafting PMMA chains was carried out by surface-initiated atom transfer radical polymerization (SI-ATRP) ${ }^{18}$. The grafting of PMMA onto the BZT-BCT nanoparticles (Scheme 1) was carried out using a similar approach as that reported for the PGMA grafting on $\mathrm{BaTiO}_{3}$ nanoparticles (see supporting information for detailed grafting and thin film preparation) ${ }^{13 \mathrm{f}}$.

\section{Preparation of free polymer and polymer nanocomposite films}

Four films were prepared and characterized (F1-F4). The solutions were prepared by mixing the components into a DMF solution (formulations described below). Each formulation was then stirred for $1 \mathrm{~h}$ to insure the formation of stable suspensions. The suspensions were poured onto a copper substrate, kept on hot plate for $1 \mathrm{~h}$ at $100^{\circ} \mathrm{C}$ for solvent evaporation. Finally pure polymer and polymer-nanocomposite thin films with a thickness of 10-20 $\mu \mathrm{m}$ were obtained.

Film 1: PMMA thin film made purely from the PMMA free polymer (that was produced by PTSC reaction with MMA), and used as a polymer only control.

Film 2: Grafted nanoparticle film was prepared from PMMA grafted BZT-BCT (82 \% polymer and $18 \%$ BZT-BCT by weight) without any additional free polymer. From the TGA results, it can be observed that the final nanocomposite contains $82 \%$ polymer (soft material) and $18 \%$ BZT-BCT (hard material)

Film 3: To draw a direct comparison and to find out the effect grafting the polymers on to the surface of the nanoparticle compared with a simple physical mixing of free polymer to the nanoparticles (F4), the following film composition was prepared. Grafted nanoparticle composite and a small amount of free polymer were utilized to increase the polymer percentage to $90 \%$ from $82 \%$ (grafted polymer material). This was achieved by adding $16 \mathrm{mg}$ of free PMMA polymer to $20 \mathrm{mg}$ of grafted nanocomposite. (In the $20 \mathrm{mg}$ grafted nanocomposite film consists of $16.4 \mathrm{mg}$ of polymer and $3.6 \mathrm{mg}$ of ceramic nanoparticles. By adding $16 \mathrm{mg}$ of free polymer, 
the final polymer composition in the film is $32.4 \mathrm{mg}$ and final ceramic composition in the film is $3.6 \mathrm{mg}$. In the overall $36 \mathrm{mg}$ of nanocomposite, $3.6 \mathrm{mg}(10 \%)$ is ceramic nanoparticles and the rest $32.4 \mathrm{mg}(90 \%)$ is polymer which is analogous to the Film F4 with respect to the same amount of polymer to nanoparticle ratio.

Film F4: A blended composite made from 90\% free PMMA polymer and 10\% un-grafted BZTBCT (without surface grafted polymer), and used as a control for simple mixing of nanoparticles and free polymer.

\section{Characterization Techniques}

In order to evaluate crystalline structure, the X-ray diffraction (XRD) profiles of four polymer/nanoparticle films investigated: 1) the free polymer PMMA alone (film F1), 2) PMMA grafted BZT-BCT (82\% polymer and 18\% BZT-BCT) (film F2), 3) a 90\% polymer by total weight blend consisting of $44.4 \%$ free PMMA and 55.6\% PMMA-grafted BZT-BCT (which contains, $44.4 \%$ free polymer by weight and an additional $45.6 \%$ grafted polymer by weight, for a total polymer content of $90 \%$ and a total inorganic BZT-BCT content of 10\%) (film F3), and 4) a 90\% PMMA free polymer with 10\% unmodified BZT-BCT blend (film F4), and BZT-BCT ceramic nanoparticles were recorded using $\mathrm{Cu} \mathrm{K}_{\alpha}$ radiation from a highly stabilized and automated Rigaku X-ray generator operated at 40kV and 40mA. The XRD data were recorded at a step size 0.02 and step scan $1 \% \mathrm{~min}$, for the entire angular range $10^{\circ}-80^{\circ}$. Fourier transform infrared spectroscopy (FT-IR, PerkinElmer spectrometer) was used to study the functional groups of PMMA before and after surface initiation. Thermogravimetric analysis (TGA) data was acquired using TA Instruments TGA 2950 Thermogravimetric Analyzer with heating rate of $20{ }^{\circ} \mathrm{C}$ per minute under $\mathrm{N}_{2}$ atmosphere. Data was processed using TA Instruments Universal Analysis software. Transmission electron (TEM) microscopy images were taken with a FEI G2 F30 Tecnai TEM operated at $200 \mathrm{kV}$.

Size exclusion chromatography was carried out on Waters model 1500 series pump (Milford, MA) with three-column series from Polymer Laboratories, consisting of PLgel $5 \mu \mathrm{m}$ Mixed D $\left(300 \times 7.5 \mathrm{~mm}^{2}\right)$ and PLgel $5 \mu \mathrm{m} 500 \AA\left(300 \times 7.5 \mathrm{~mm}^{2}\right)$ and PLgel $5 \mu \mathrm{m} 50 \AA\left(300 \times 7.5 \mathrm{~mm}^{2}\right)$ columns. The system was fitted with a Model 2487 differential refractometer detector. THF was used as mobile phase (1 mL/min flow rate). The calculated molecular weight was based on 
calibration using linear polystyrene standards. Data was collected and processed using Precision Acquire software. The Fourier transform infrared (FTIR) spectroscopy was performed using a NEXUS 670 FT-IR SEP. The analyte was mixed with $\mathrm{KBr}$ and ground into a fine powder and compacted into a pellet by applying pressure.

Dielectric characterization of the samples was conducted by Broadband Dielectric Spectroscopy (DBS) in the frequency range of $100 \mathrm{~Hz}$ to $1 \mathrm{MHz}$ using a HP4284A inductance-capacitanceresistance (LCR) meter by using copper foil as bottom electrode and silver paste as top electrode for these films. Electrical breakdown voltage of the capacitor metal-insulator-metal (MIM) configuration was measured at room temperature using Trek $(10 \mathrm{kV})$ high voltage amplifier.

\section{Results and discussion}

\section{Crystal structure and FT-IR spectra}

Figure 1 shows the room-temperature XRD patterns for films F1-F4 along with pure BZT-BCT ceramic nanoparticles with angle $2 \theta$ (degree) ranging from $20^{\circ}$ to $80^{\circ}$. It is evident that all of the sintered ceramics were crystallized into a single-phase perovskite structure. The diffraction peaks of the BZT-BCT were indexed to the tetragonal crystal structure with space group $(P 4 m m)$ in agreement with the respective Joint Committee on Powder Diffraction Standards (JCPDS) card number: 05-0626 [Joint Committee on Powder Diffraction Standards (JCPDS) card no 05-0626]. XRD diffraction pattern for pure PMMA is also shown in Fig.1. Pure PMMA (film-F1) shows a predominant and broad characteristic peaks, with a maximum at $2 \theta \sim 15.5^{\circ}$ and along with other peaks $29.43^{\circ}, 41^{\circ}, 51.37^{\circ}$. These broad peaks indicate the amorphous nature of the polymer. XRD patterns are in agreement with the respective Joint Committee on Powder Diffraction Standards (JCPDS) card no 13-0835. For all the polymer-nanocomposites films (F2-F4), the high intensity of $\mathrm{Cu}$ substrate suppressed the peak intensity of BZT-BCT nanoparticles.

In the present work, 2-(4-chlorosulfonylphenyl) ethyl trichlorosilane (CTCS) coupling agent was immobilized onto the nanoparticles to provide graft-able surface functionalities. CTCS attaches to the nanoparticles surface by hydrolysis of the chlorosilyl functionality to form the $\mathrm{Si}-\mathrm{O}-\mathrm{Si}$ covalent bonds with inorganic surfaces, such as glass ${ }^{18 \mathrm{~b}}$. The chlorosulfonylphenyl group $\left(-\mathrm{Ph}-\mathrm{SO}_{2} \mathrm{Cl}\right)$ was selected because it is one of the best initiating groups for ATRP ${ }^{19}$. As shown in Fig. 2 (a), the FTIR spectrum of pristine BZT-BCT ceramic nanoparticles shows only three 
absorption bands at $3420 \mathrm{~cm}^{-1}, 1437 \mathrm{~cm}^{-1}$ and $581 \mathrm{~cm}^{-1}$, a broad absorption band representing some $-\mathrm{OH}$ groups that are present on the surface of BZT-BCT, the stretching vibration of $-\mathrm{CO}_{3}{ }^{2-}$ from the residual metal $\mathrm{CO}_{3}$ from the starting materials and the vibration mode of a metal-dioxo bridge, respectively ${ }^{20}$.

Due to the native presence of $-\mathrm{OH}$ groups on the surface of BZT-BCT, the ATRP initiating sites could be introduced by the reaction of CTCS with residual surface - $\mathrm{OH}$ groups. The presence of absorption band at $1115 \mathrm{~cm}^{-1}$ (Si-O-particle) in the FTIR spectrum of BZT-BCT-CTCS (Fig. 2 b) suggested that the silane was successfully introduced onto the surface of $\mathrm{BaTiO}_{3}$. The absorption bands at $1374 \mathrm{~cm}^{-1}$ (the $\mathrm{S}=\mathrm{O}$ groups) were clearly detected, providing further indication that CTCS was successfully grafted onto the surface of $\mathrm{BaTiO}_{3}$. However, the absorption band at $\sim 544 \mathrm{~cm}^{-1}$ (the S-Cl stretching) was completely masked by strong metaldioxo bridge absorbance. The Fourier transform infrared (FTIR) spectra of the pure PMMA (F1), and surface initiated ATRP PMMA grafted BZT-BCT nanocomposites (F2) are shown in the wave number ranging from 400 to $4000 \mathrm{~cm}^{-1}$ (shown in Fig.2). The characteristic absorption band at around $1727 \mathrm{~cm}^{-1}$ due to strong ester carbonyl signal of PMMA (Fig. $2 \mathrm{~d}$ ) is also present in PMMA grafted BZT-BCT nanocomposites (Fig. 2 c), but this band is completely absent in in the FTIR spectrum of BZT-BCT-CTCS (Fig. 2 b) before graft polymerization of MMA, indicating the PMMA chains are grafted onto BZT-BCT nanoparticles. The presence of grafted PMMA onto BZT-BCT nanoparticles due to strong ester carbonyl signals $\left(1730 \mathrm{~cm}^{-1}\right)^{21}$ of PMMA (Fig. 2 d) is consistent with a substantial weight loss of TGA spectrum (Fig. 3 c) of PMMA grafted BZT-BCT and complete coverage BZT-BCT nanoparticles PMMA in the of the TEM images of PMMA grafted BZT-BCT (Fig. 4 c).

\section{Thermal Gravimetric Analysis (TGA)}

TGA measurements (Fig. 3) also confirmed that immobilization of ATRP initiating sites onto BZT-BCT. Pristine BZT-BCT nanoparticles (Fig. 3 (a)) shows about $1.5 \%$ mass loss at $700{ }^{\circ} \mathrm{C}$ that might be due to the adsorbed moisture and surface-OH groups. The TGA curve of BZTBCT-CTCS nanoparticles (Fig. 2 (b)) shows an additional mass loss $(5.5 \%)$ at $700{ }^{\circ} \mathrm{C}$ as compared to the BZT-BCT, providing further evidence that ATRP initiating sites were immobilized onto nanoparticles successfully. TGA was most useful in quantifying the mass of 
PMMA grafted onto the BZT-BCT nanoparticles. After the grafting reaction, BZT-BCT-gPMMA exhibited a weight loss of $80.1 \%$ upon heating to $700{ }^{\circ} \mathrm{C}$ (Fig. 3c). The majority of the mass loss occurred between $450{ }^{\circ} \mathrm{C}$ and $505{ }^{\circ} \mathrm{C}$, with an onset of $220{ }^{\circ} \mathrm{C}$ and an inflection point of $480{ }^{\circ} \mathrm{C}$, similar to what is observed with pure PMMA (onset at 325, inflection point at 415 ${ }^{\circ} \mathrm{C}$ ). This can be interpreted as grafting sufficient PMMA onto the surface of the nanoparticles to account for $\sim 80 \%$ of the total weight of the BZT-BCT-g-PMMA.

\section{Transmission Electron Microscopy (TEM)}

Morphological characterization and surface structure of PMMA grafted BZT-BCT nanoparticles were analyzed by TEM to directly observe the nanoscale behavior of grafted nanoparticles. From Fig. 4 it was clear that the average dimensions of nanoparticles were around $50 \mathrm{~nm}$ and there was no aggregation among the particles. After the reaction of nanoparticles with CTCS, there is almost no change in the morphology; however, the particles have been aggregated to some extent during their reaction with CTCS. Similarly, after the graft polymerization of MMA, the PMMA grafted BZT-BCT particles exhibit some aggregation. It can be clearly seen in the TEM images that the BZT-BCT nanoparticles are completely covered by grafted PMMA. These results, in addition to the FT-IR and TGA data, clearly confirm that PMMA has been successfully grafted from the BZT-BCT surface.

\section{Dielectric properties}

Dielectric properties of all the samples were measured using an LCR meter (HP 4284A) at different frequencies ranging from $100 \mathrm{~Hz}$ to $1 \mathrm{MHz}$ as shown in Fig. 5. Using the capacitance values, the dielectric constant for all the parallel plate dielectric capacitors was calculated at the same frequency range from $100 \mathrm{~Hz}$ to $1 \mathrm{MHz}$ at room temperature using the following equation (2).

$$
\epsilon=\frac{C * d}{\epsilon_{0} * A}
$$


where $\varepsilon$ is the dielectric constant of the material, $\mathrm{C}$ is the measured capacitance $(\mathrm{pF})$ by the LCR meter, $\mathrm{d}$ is the thickness of the capacitor measured in centimeters $(\mathrm{cm}), \varepsilon_{0}$ is the permittivity of the free space or vacuum $(8.854 \mathrm{pF} / \mathrm{m})$, and $\mathrm{A}$ is the surface area of the electrode of the capacitor calculated in $\mathrm{cm}^{2}$. The dielectric constant $(\varepsilon)$ of a capacitor represents the ability of a material to store the charges during the dielectric polarization. In addition to high dielectric constant, low dielectric losses $(\tan \delta$ ) are mandatory for integral thin film capacitors, electrostriction systems for artificial muscles and electric stress control devices applications ${ }^{9 \mathrm{~b}}$. Dielectric loss is another important parameter in electrical capacitor applications. In general, capacitor performance is determined from the dielectric loss parameter; high dielectric loss will tend to dissipate a fraction of the stored energy in the form of heat and is detrimental to capacitor function.

In our earlier investigation we report high dielectric constant $(\varepsilon \sim 400$ at $100 \mathrm{~Hz})$, low dielectric loss ( $\tan \delta \sim 0.02$ ) properties at room temperature for BZT-BCT ceramic nanoparticles ${ }^{17}$. These ceramic nanoparticles have shown diffuse phase transition behavior for capacitor applications. Fig. 5 shows the frequency dependence of the dielectric constant and dielectric loss (tan $\delta)$ of the PMMA and polymer nanocomposites films investigated in the frequency range from $100 \mathrm{~Hz}$ to 1 $\mathrm{MHz}$ at room temperature. All the films have shown high dielectric constant at low frequency $(100 \mathrm{~Hz})$ and low dielectric constant at high frequency $(1 \mathrm{MHz})$. This decrease in dielectric constant with frequency is attributed to the permanent dipole moments from the ferroelectric behavior of BZT-BCT ceramics that provide spontaneous polarization at room temperature thereby enhancing the dielectric constant values of the capacitor materials ${ }^{2 b}$.

The dielectric constant of the polymer grafted nanocomposites $(\mathrm{F} 2)$ is significantly greater than that of F1, F3, F4, the dielectric constant values are $\varepsilon \sim 6.5(\mathrm{~F} 1), 56.55(\mathrm{~F} 2), 36(\mathrm{~F} 3), 32.34(\mathrm{~F} 4)$, respectively at $100 \mathrm{~Hz}$. The dielectric constant of the core-shell structured PMMA graft BZTBCT nanocomposite (F2) increased to 56.55, nearly 10 times that of the pure PMMA polymer films ( $\varepsilon \sim 6.5)$. Significant dielectric constant increase could be explained by a number of important differences in the two films compared. Most obviously, the introduction of inorganic high dielectric constant $(\varepsilon \sim 400)$ of BZT-BCT as shown in Fig.S2 ${ }^{17}$ filler particles are expected to improve the dielectric constant over PMMA alone. A second factor is that the covalent polymer-inorganic interface might allow large amounts of charge to accumulate between the two 
distinct phases, generating interfacial polarization. In addition, the increased surface polarity caused by the introduction of polar initiating groups may play a role in improving the dielectric constant. This observation is consistent with previous reports which demonstrate that the surface functional groups at the nanoparticles/polymer matrix interface can have a profound effect on the electrical properties yielding improved dielectric properties for nanocomposites ${ }^{5,6 b, 13 f, 22}$.

Perhaps a more revealing comparison is that of film 3 against films 2 and 4 . Film 3 only differs from film 2 by the addition of un-grafted PMMA ( $44.4 \%$ by weight). The significant drop in the dielectric constant suggests that substantial amounts of un-grafted PMMA only reduce the materials dielectric constant-consistent with the reduced dielectric constant of PMMA with respect to BZT-BCT. However, comparison of film 3 against film 4 provides additional insight. When comparing two films with the same amount of polymer (90\%) and BZT-BCT (10\%) content, the film with the surface grafted polymer performed measurably better, suggesting that the surface layer of polymer did play a role in improving the dielectric constant of these materials. Compared to the pure ungrafted BZT-BCT nanoparticles film F2 has shown significant increase in the breakdown strength. BDS for the pure nanoparticles $\left(\sim 0.073 \mathrm{MVcm}^{-1}\right)$ was significantly enhanced for the grafted film $\left(\mathrm{F} 2 \sim 3 \mathrm{MVcm}^{-1}\right)$ by almost 40 times. Even though, the dielectric constant for the film F2 $(\sim 56.55)$ was 4 times less than that of pure BZTBCT nanoparticles ( 400), the improvement in the breakdown and its quadratic dependence on the final energy density results in much higher energy storage values for the grafted nanoparticles film (F2) $\left(\sim 22.5 \mathrm{~J} / \mathrm{cm}^{3}\right.$ at $\left.3 \mathrm{MV} / \mathrm{cm}\right)$ than the pure BZT-BCT nanoparticles $(\sim 0.6$ $\mathrm{J} / \mathrm{cm}^{3}$ at $\left.0.073 \mathrm{MV} / \mathrm{cm}\right)$.

Fig. 5(b) also shows that the dielectric loss ( $\tan \delta$ ) of F1 0.0188, F2 0.02786, F3 0.06250 and F4 0.08129 respectively at $100 \mathrm{~Hz}$. Dielectric properties of pure BZT-BCT ceramics were displayed in Fig.S2. Over the whole frequency range measured the dielectric loss of the grafted and un-grafted nanocomposites is higher than of the pure PMMA. Although the relative importance of these parameters is not completely understood, it is clear the grafted BZT-BCT exhibit superior properties to the pure PMMA polymer itself. Meanwhile, the loss tangent of the nanocomposites remains quite low. The loss tangent for pure PMMA and for all other grafted and un-grafted polymer nanocomposite materials exhibited little variation in the frequency range 
from $100 \mathrm{~Hz}$ to $1 \mathrm{MHz}$. As the frequency increases, dielectric loss for all the films decreased. The higher value of dielectric loss $(\tan \delta)$ at a low frequency can be attributed to the space charge relaxation polarization mechanism. The dielectric loss of the nanocomposite was found to be slightly higher than the polymer matrix. From these results we can conclude that polymer grafted nanoparticles could be a promising material for fabricating dielectric materials for high dielectric constant films. We can see that the dielectric constant of these nanocomposites $(\varepsilon \sim 56.55)$ is much higher than that of PGMA grafted $\mathrm{BaTiO}_{3}$ nanoparticles $(\varepsilon \sim 15)$ [15]; however dielectric constant for present pure PMMA polymer $(\varepsilon \sim 6.5)$ is similar $(\varepsilon \sim 5)$ to what has been previously reported by Liyuan et al. ${ }^{13 \mathrm{~d}}$. It is believed a significant portion of the increase in dielectric constant can be attributed to partial substitution of $\mathrm{Ca}^{2+}$ at the $\mathrm{A}$-site and $\mathrm{Zr}^{4+}$ at the $\mathrm{B}$ cite in typical $\mathrm{ABO}_{3}$ type perovskite $\mathrm{BaTiO}_{3}$. By suitable site engineering at both the $\mathrm{Ba}^{2+}$ and the $\mathrm{Ti}^{4+}-$ sites in $\mathrm{BaTiO}_{3}$, the dielectric properties can be optimized ${ }^{17,24}$.

Electric field dependent electrical energy density of pure PMMA (F1), polymer grafted BZTBCT (F2) and partially blended film (F3) and un-grafted film (F4) were shown in Fig.6. Electrical energy storage of these dielectric capacitors was calculated using equation (1) due to linear polarization-electric field behavior as shown in Fig.S1 (supporting information). Leakage current behaviors of these films were also shown in Fig.S3 before the dielectric breakdown occurred. As the electric field increases electrical energy density of films increased drastically. It

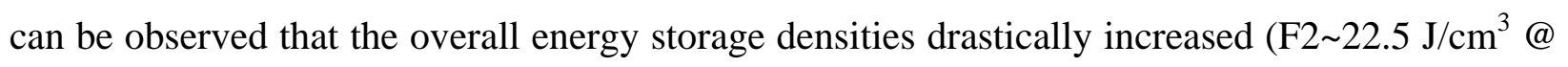
$3 \mathrm{MV} / \mathrm{cm}$ ) for polymer-grafted films when compared to all other films (F1 $10.3 \mathrm{~J} / \mathrm{cm}^{3}, \mathrm{~F} 3 \sim$ $14.34 \mathrm{~J} / \mathrm{cm}^{3}, \mathrm{~F} 4 \sim 12.88 \mathrm{~J} / \mathrm{cm}^{3}$ ), however the maximum electric field (before the breakdown field occurred) of pure polymer is higher ( $\sim \mathrm{MV} / \mathrm{cm})$ than that of nanocomposite films ( $\sim 3 \mathrm{MV} / \mathrm{cm})$. The enhanced energy density in the polymer-grafted nanoparticles mainly originates from the increased dielectric constant. Considering that, significant increase in dielectric constant of nanocomposites and comparable dielectric losses were due to the grafted polymer on the nanoparticles. Surface polymer grafting holds significant promise for further optimizing the dielectric properties of nanoparticles-based composite materials ${ }^{13 \mathrm{~d}, 23}$.

Fig.7 shows the variation of ac electrical conductivity $\left(\sigma_{\mathrm{ac}}\right)$ for pure PMMA and polymer nanocomposites as a function of frequency $(100 \mathrm{~Hz}-1 \mathrm{MHz})$. The ac conductivity was calculated 
from dielectric properties using the relation $\left[\sigma_{\mathrm{ac}}=\varepsilon_{\mathrm{o}} \varepsilon_{\mathrm{r}} \omega \tan (\delta)\right]$. In most of the disordered materials, ac conductivity is directly proportional to the frequency. It is well known that, in large polaron hopping, the ac conductivity decreases with frequency whereas in small polaron hopping it increases with frequency. In the present case for all the samples, the plots for ac conductivity measurements are linear and increasing with respect to frequency, indicating the conduction is due to a small polaron hopping mechanism. Pure polymer capacitors have shown lower $\sigma_{\mathrm{ac}}\left(10^{-11}\right.$ $\mathrm{S} / \mathrm{cm}$ at $100 \mathrm{~Hz})$ than that of all polymer-nanocomposites $\left(10^{-10} \mathrm{~S} / \mathrm{cm}\right.$ at $\left.100 \mathrm{~Hz}\right)$. The electrical conductivity of the samples, however exhibits strong dependence on the frequency. One can see that the introduction of BZT-BCT nanoparticles slightly increases the electrical conductivity of the nanocomposites $\left(10^{-7} \mathrm{~S} / \mathrm{cm}\right.$ at $\left.1 \mathrm{MHz}\right)$. The overall electrical conductivity of pure polymer and polymer nanocomposites were low due low dielectric losses. The ac electrical conductivity of all the samples increases with the increase of frequency for all the samples and this is only slightly higher than that of pure PMMA over the whole frequency range measured, indicating the good insulating properties for all the samples ${ }^{13 d}$. The low electrical conductivity of nanocomposites is attributed to capping of BZT-BCT nanoparticles by insulating PMMA polymer shell and homogeneous dispersion in the polymer matrix, which prevented the electron conduction and when compared to pure PMMA, polymer grafted nanocomposites (BZT-BCT-gPMMA) have a higher fraction of isotactic structure, which resulted in the lower leakage current and lower dielectric loss of these nanocomposites prepared by ATRP ${ }^{13 d}$.

\section{Conclusions}

BZT-BCT-PMMA nanocomposites with a PMMA coating were successfully prepared by SIATRP of MMA from the surface of BZT-BCT nanoparticles. A range of electronic measurements were utilized to compare the electric properties of pure PMMA film and BZTBCT-PMMA nanocomposites films. AC conductivity measurements were in good agreement with universal power law. Low electrical conductivities on the order of $10^{-11}$ to $10^{-7} \mathrm{~S} / \mathrm{cm}$ were observed in both the pure and nanocomposite films. Improved dielectric properties were observed for BZT-BCT-PMMA nanocomposite films, and are attributed to the even dispersion of nanoparticles within the polymer film, due to their improved compatibility upon grafting. Also, comparing films that were made from simple polymer/ceramic mixing with grafted BZTBCT-PMMA/free polymer and pure BZT-BCT-PMMA nanocomposite reveals the importance of 
covalent attachment between nanoparticle surface and polymer. Specifically, the nanocomposite films prepared from PMMA-grafted BZT-BCT nanoparticles exhibited high-energy storage densities ( $\sim 22.5 \mathrm{~J} / \mathrm{cm}^{3}$ at $\left.3 \mathrm{MV} / \mathrm{cm}\right)$ with respect to bulk PMMA $\left(\sim 10.39 \mathrm{~J} / \mathrm{cm}^{3}\right.$ at $\left.6 \mathrm{MV} / \mathrm{cm}\right)$. The significant improvement observed for polymer grafted BZT-BCT nanocomposites highlights the promise of grafted nanomaterials for optimizing future high-energy storage capacitor materials.

Acknowledgements: This work was supported by the National Science Foundation under grant NSF-EFRI RESTOR \# 1038272. Funding for RE (Smart Materials Design, Analysis, and Processing consortium (SMATDAP) funded by the National Science Foundation under cooperative agreement IIA-1430280 and ME (Eppley Foundation) are also acknowledged.

\section{Figure Captions}

Scheme 1. Synthesis of BZT-BCT-PMMA core-shell nanoparticles by SI-ATRP of MMA from BZT-BCT nanoparticles.

Fig.1. X-ray diffraction patterns of BZT-BCT powder ceramics and the films (F1-F4)

Fig. 2. FTIR spectra of (a) as-prepared BZT-BCT, (b) BZT-BCT-CTCS, (c) BZT-BCT-PMMA, and (d) pure PMMA.

Fig.3. TGA curves of (a) as-prepared BZT-BCT, (b) BZT-BCT-CTCS, (c) PMMA-g-BZT-BCT, and (d) pure PMMA.

Fig.4. TEM images of (a) as-prepared BZT-BCT, (b) BZT-BCT-CTCS, (c) PMMA-g-BZT-BCT. Fig.5 (a,b). Frequency dependent dielectric properties of (F1-F4) nanocomposite films at 100 $\mathrm{Hz}-1 \mathrm{MHz}$.

Fig.6. Electric field dependent energy density properties of (F1-F4) polymer nanocomposite films.

Fig.7. Variation of A.C. conductivity with frequency of (F1-F4) polymer nanocomposite.

Fig.S1. Typical polarization-electric field (before dielectric breakdown occurred) loops for linear dielectric PMMA-g-BZT-BCT polymer nanocomposite films.

Fig.S2 (a, b) The temperature dependence of the dielectric constant and dielectric loss of $\left[\left(\mathrm{BaZr}_{0.2} \mathrm{Ti}_{0.80}\right) \mathrm{O}_{3}\right] 1-\mathrm{x}-\left[\left(\mathrm{Ba}_{0.70} \mathrm{Ca}_{0.30}\right) \mathrm{TiO}_{3}\right] \mathrm{x}(\mathrm{x}=0.20)$ - (BZT-BCT $)$ ceramics. 
Fig.S3 Electric field dependent leakage current behavior of (F1-F4) polymer and polymer nanocomposite.

\section{References}

1. (a) Shuvo, M. A. I.; Khan, M. A. R.; Karim, H.; Morton, P.; Wilson, T.; Lin, Y., Investigation of Modified Graphene for Energy Storage Applications. ACS Applied Materials \& Interfaces 2013, 5 (16), 7881-7885; (b) Ishtiaque Shuvo, M. A.; Rodriguez, G.; Islam, M. T.; Karim, H.; Ramabadran, N.; Noveron, J. C.; Lin, Y., Microwave exfoliated graphene oxide/TiO2 nanowire hybrid for high performance lithium ion battery. Journal of Applied Physics 2015, 118 (12), 125102.

2. (a) Rajib, M.; Arif Ishtiaque Shuvo, M.; Karim, H.; Delfin, D.; Afrin, S.; Lin, Y., Temperature influence on dielectric energy storage of nanocomposites. Ceramics International 2015, 41 (1, Part B), 1807-1813; (b) Rajib, M.; Martinez, R.; Shuvo, M.; Karim, H.; Delfin, D.; Afrin, S.; Rodriguez, G.; Chintalapalle, R.; Lin, Y., Enhanced Energy Storage of Dielectric Nanocomposites at Elevated Temperatures. International Journal of Applied Ceramic Technology 2016, 13 (1), 125-132.

3. Lu, Y.; Claude, J.; Neese, B.; Zhang, Q.; Wang, Q., A Modular Approach to Ferroelectric Polymers with Chemically Tunable Curie Temperatures and Dielectric Constants. Journal of the American Chemical Society 2006, 128 (25), 8120-8121.

4. Phougat, N.; Vasudevan, P.; Nalwa, H. S., Chapter 8 - Metallophthalocyanines as High-Dielectric Constant Materials. In Handbook of Low and High Dielectric Constant Materials and Their Applications, Academic Press: Burlington, 1999; pp 329-427.

5. Puli, V. S.; Elupula, R.; Riggs, B. C.; Grayson, S. M.; Katiyar, R. S.; Chrisey, D. B., Surface modified BaTiO 3polystyrene nanocomposites for energy storage. International Journal of Nanotechnology 2014, 11 (9-1011), 910-920.

6. (a) Li, J. Y.; Zhang, L.; Ducharme, S., Electric energy density of dielectric nanocomposites. Applied Physics Letters 2007, 90 (13), 132901; (b) Riggs, B. C.; Elupula, R.; Rehm, C.; Adireddy, S.; Grayson, S. M.; Chrisey, D. B., Click-In Ferroelectric Nanoparticles for Dielectric Energy Storage. ACS Applied Materials \& Interfaces 2015, 7 (32), 17819-17825.

7. Banerjee, S.; Cook-Chennault, K. A., Influence of Al Particle Size and Lead Zirconate Titanate (PZT) Volume Fraction on the Dielectric Properties of PZT-Epoxy-Aluminum Composites. Journal of Engineering Materials and Technology 2011, 133 (4), 041016-041016. 


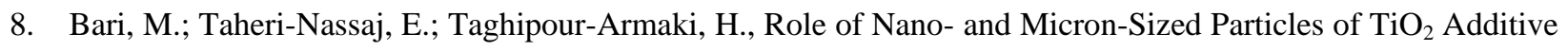
on Microwave Dielectric Properties of Li2ZnTi3O8 - 4 wt\% TiO2 Ceramics. Journal of the American Ceramic Society 2013, 96 (12), 3737-3741.

9. (a) Krishnamoorti, R., Strategies for Dispersing Nanoparticles in Polymers. MRS Bulletin 2007, 32 (04), 341347; (b) Xie, L.; Huang, X.; Yang, K.; Li, S.; Jiang, P., "Grafting to" route to PVDF-HFP-GMA/BaTiO3 nanocomposites with high dielectric constant and high thermal conductivity for energy storage and thermal management applications. Journal of Materials Chemistry A 2014, 2 (15), 5244-5251.

10. Dang, Z.-M.; Wang, H.-Y.; Xu, H.-P., Influence of silane coupling agent on morphology and dielectric property in BaTiO3/polyvinylidene fluoride composites. Applied Physics Letters 2006, 89 (11), 112902.

11. Kim, P.; Doss, N. M.; Tillotson, J. P.; Hotchkiss, P. J.; Pan, M.-J.; Marder, S. R.; Li, J.; Calame, J. P.; Perry, J. W., High Energy Density Nanocomposites Based on Surface-Modified BaTiO3 and a Ferroelectric Polymer. ACS Nano 2009, 3 (9), 2581-2592.

12. Li, J.; Claude, J.; Norena-Franco, L. E.; Seok, S. I.; Wang, Q., Electrical Energy Storage in Ferroelectric Polymer Nanocomposites Containing Surface-Functionalized BaTiO3 Nanoparticles. Chemistry of Materials 2008, 20 (20), 6304-6306.

13. (a) Jung, H. M.; Kang, J.-H.; Yang, S. Y.; Won, J. C.; Kim, Y. S., Barium Titanate Nanoparticles with Diblock Copolymer Shielding Layers for High-Energy Density Nanocomposites. Chemistry of Materials 2010,22 (2), 450-456; (b) Guo, N.; DiBenedetto, S. A.; Kwon, D.-K.; Wang, L.; Russell, M. T.; Lanagan, M. T.; Facchetti, A.; Marks, T. J., Supported Metallocene Catalysis for In Situ Synthesis of High Energy Density Metal Oxide Nanocomposites. Journal of the American Chemical Society 2007, 129 (4), 766-767; (c) Yang, K.; Huang, X.; Xie, L.; Wu, C.; Jiang, P.; Tanaka, T., Core-Shell Structured Polystyrene/BaTiO3 Hybrid Nanodielectrics Prepared by In Situ RAFT Polymerization: A Route to High Dielectric Constant and Low Loss Materials with Weak Frequency Dependence. Macromolecular Rapid Communications 2012, 33 (22), 1921-1926; (d) Xie, L.; Huang, X.; Wu, C.; Jiang, P., Core-shell structured poly(methyl methacrylate)/BaTiO 3 nanocomposites prepared by in situ atom transfer radical polymerization: a route to high dielectric constant materials with the inherent low loss of the base polymer. Journal of Materials Chemistry 2011, 21 (16), 5897-5906; (e) Yang, K.; Huang, X.; Huang, Y.; Xie, L.; Jiang, P., Fluoro-Polymer@BaTiO 3 Hybrid Nanoparticles Prepared via RAFT Polymerization: Toward Ferroelectric Polymer Nanocomposites with High Dielectric Constant and Low Dielectric Loss for Energy Storage Application. Chemistry of Materials 2013, 25 (11), 2327-2338; (f) Ejaz, M.; Puli, V. S.; Elupula, R.; Adireddy, S.; Riggs, B. C.; Chrisey, D. B.; Grayson, S. M., Core-shell structured poly (glycidyl methacrylate)/BaTiO3 nanocomposites prepared by surface-initiated atom transfer radical polymerization: A novel material for high energy density dielectric storage. Journal of Polymer Science Part A: Polymer Chemistry 2015, 53 (6), 719-728.

14. Stefanescu, E. A.; Tan, X.; Lin, Z.; Bowler, N.; Kessler, M. R., Multifunctional PMMA-Ceramic composites as structural dielectrics. Polymer 2010, 51 (24), 5823-5832. 
15. Ejaz, M.; Puli, V. S.; Elupula, R.; Adireddy, S.; Riggs, B. C.; Chrisey, D. B.; Grayson, S. M., Core-shell structured poly(glycidyl methacrylate)/BaTiO3 nanocomposites prepared by surface-initiated atom transfer radical polymerization: A novel material for high energy density dielectric storage. Journal of Polymer Science Part A: Polymer Chemistry 2015, 53 (6), 719-728.

16. (a) Matyjaszewski, K.; Tsarevsky, N. V., Nanostructured functional materials prepared by atom transfer radical polymerization. Nat Chem 2009, 1 (4), 276-288; (b) Huang, X.; Jiang, P., Core-Shell Structured High-k Polymer Nanocomposites for Energy Storage and Dielectric Applications. Advanced Materials 2015, 27 (3), 546-554; (c) Chen, Z.; Xie, L.; Huang, X.; Li, S.; Jiang, P., Achieving large dielectric property improvement in polymer/carbon nanotube composites by engineering the nanotube surface via atom transfer radical polymerization. Carbon 2015, 95, 895-903; (d) Zhu, M.; Huang, X.; Yang, K.; Zhai, X.; Zhang, J.; He, J.; Jiang, P., Energy Storage in Ferroelectric Polymer Nanocomposites Filled with Core-Shell Structured Polymer@BaTiO 3 Nanoparticles: Understanding the Role of Polymer Shells in the Interfacial Regions. ACS Applied Materials \& Interfaces 2014, 6 (22), 19644-19654.

17. Venkata Sreenivas, P.; Ashok, K.; Douglas, B. C.; Tomozawa, M.; Scott, J. F.; Ram, S. K., Barium zirconatetitanate/barium calcium-titanate ceramics via sol-gel process: novel high-energy-density capacitors. Journal of Physics D: Applied Physics 2011, 44 (39), 395403.

18. (a) Ejaz, M.; Yamamoto, S.; Ohno, K.; Tsujii, Y.; Fukuda, T., Controlled Graft Polymerization of Methyl Methacrylate on Silicon Substrate by the Combined Use of the Langmuir-Blodgett and Atom Transfer Radical Polymerization Techniques. Macromolecules 1998, 31 (17), 5934-5936; (b) Ejaz, M.; Tsujii, Y.; Fukuda, T., Controlled grafting of a well-defined polymer on a porous glass filter by surface-initiated atom transfer radical polymerization. Polymer 2001, 42 (16), 6811-6815.

19. Percec, V.; Barboiu, B., "Living" Radical Polymerization of Styrene Initiated by Arenesulfonyl Chlorides and CuI(bpy)nCl. Macromolecules 1995, 28 (23), 7970-7972.

20. Chang, S.-J.; Liao, W.-S.; Ciou, C.-J.; Lee, J.-T.; Li, C.-C., An efficient approach to derive hydroxyl groups on the surface of barium titanate nanoparticles to improve its chemical modification ability. Journal of Colloid and Interface Science 2009, 329 (2), 300-305.

21. Ejaz, M.; Sunkara, B.; Kamboj, L.; He, J.; John, V. T.; Pesika, N. S.; Grayson, S. M., Facile one-pot method of initiator fixation for surface-initiated atom transfer radical polymerization on carbon hard spheres. Journal of Polymer Science Part A: Polymer Chemistry 2013, 51 (15), 3314-3322.

22. (a) Adireddy, S.; Puli, V. S.; Lou, T. J.; Elupula, R.; Sklare, S.; Riggs, B. C.; Chrisey, D. B., Polymer-ceramic nanocomposites for high energy density applications. Journal of Sol-Gel Science and Technology 2014, 1-6; (b) Douglas B. Chrisey Shiva Adireddy, V. S. Puli., Samuel C. Sklare, Ravinder Elupula, Tiffany J. Lou, Scott Grayson, Flexible Ferroelectric Polymer-Nanocrystal Composite Films for Large-Scale Capacitive Energy Storage. Ferroelectrics: Principles, Structure and Applications ,Nova Science Publishers, Inc., 
New York 2014, (ISBN: 978-1-59454-061-5); (c) Riggs, B. C.; Adireddy, S.; Rehm, C. H.; Puli, V. S.; Elupula, R.; Chrisey, D. B., Polymer Nanocomposites for Energy Storage Applications. Materials Today: Proceedings 2015, 2 (6), 3853-3863; (d) Riggs, B. C.; Elupula, R.; Grayson, S. M.; Chrisey, D. B., Photonic curing of aromatic thiol-ene click dielectric capacitors via inkjet printing. Journal of Materials Chemistry A 2014, 2 (41), 17380-17386; (e) Riggs, B. C.; Elupula, R.; Puli, V. S.; Grayson, S. M.; Chrisey, D. B., Dielectric Properties of UV Cured Thick Film Polymer Networks through High Power Xenon Flash Lamp Curing. MRS Proceedings 2014, 1630, mrsf13-1630-o06-38; (f) Wang, Q.; Zhu, L., Polymer nanocomposites for electrical energy storage. Journal of Polymer Science Part B: Polymer Physics 2011, 49 (20), 1421-1429.

23. Rahimabady, M.; Qun Xu, L.; Arabnejad, S.; Yao, K.; Lu, L.; Shim, V. P. W.; Gee Neoh, K.; Kang, E.-T., Poly(vinylidene fluoride-co-hexafluoropropylene)-graft-poly(dopamine methacrylamide) copolymers: A nonlinear dielectric material for high energy density storage. Applied Physics Letters 2013, 103 (26), 262904.

24. Puli, V. S.; Pradhan, D. K.; Chrisey, D. B.; Tomozawa, M.; Sharma, G. L.; Scott, J. F.; Katiyar, R. S., Structure, dielectric, ferroelectric, and energy density properties of $(1-\mathrm{x}) \mathrm{BZT}-\mathrm{xBCT}$ ceramic capacitors for energy storage applications. Journal of Materials Science 2012, 48 (5), 2151-2157. 
Scheme 1.

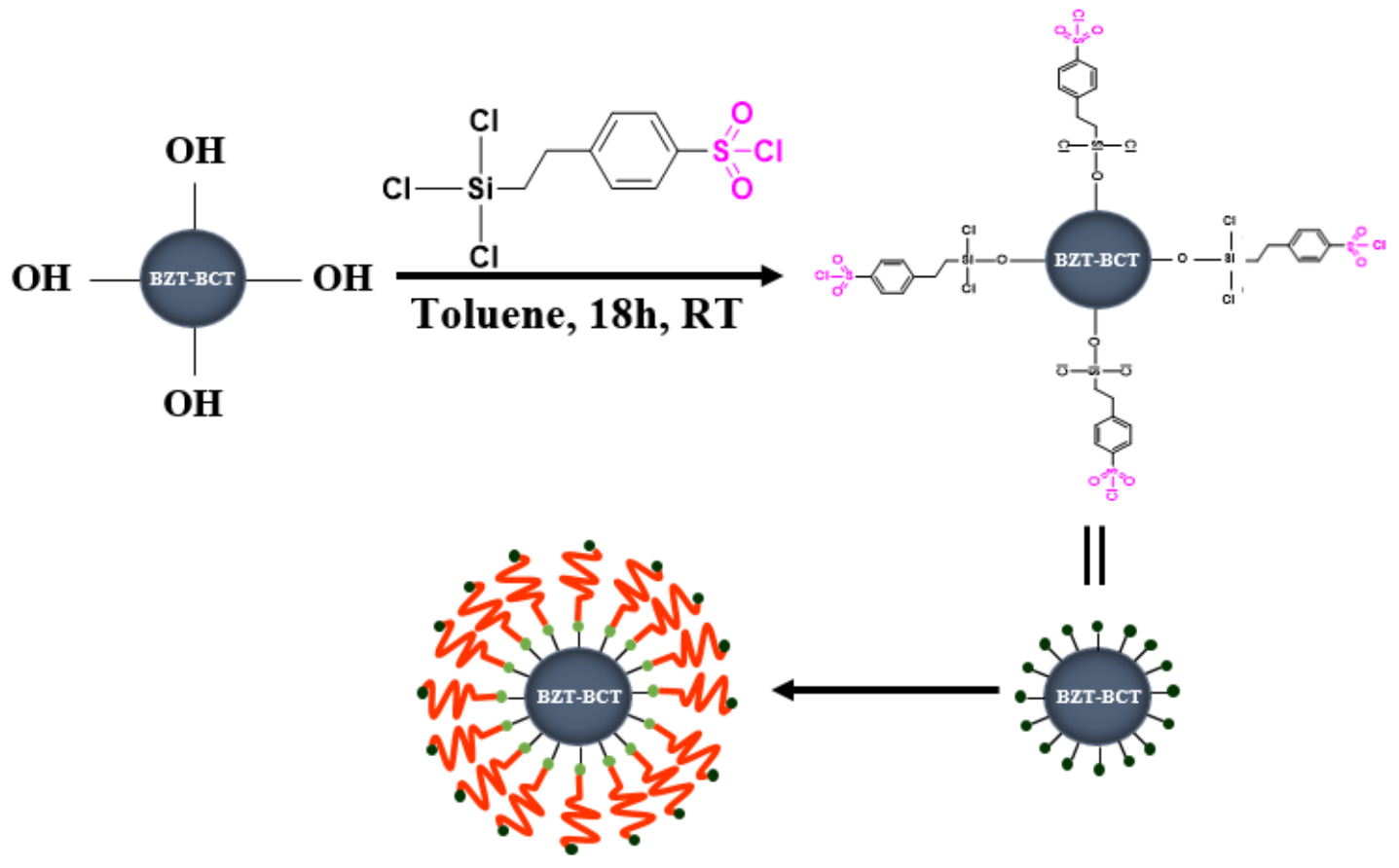

Figure 1

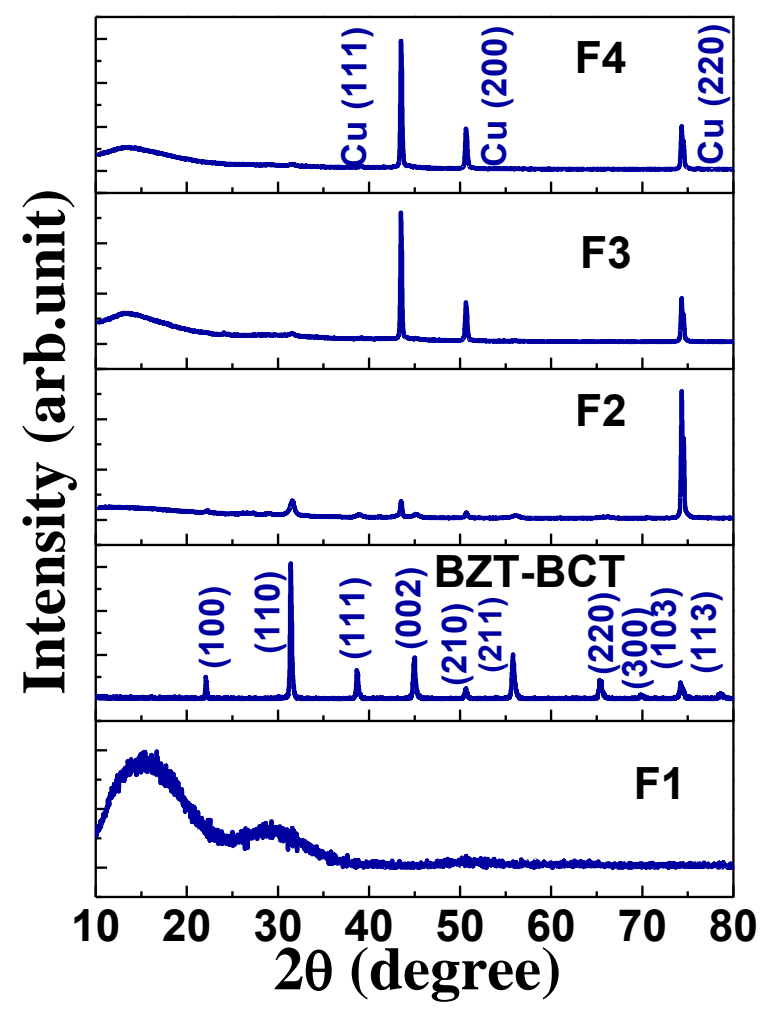


Figure 2

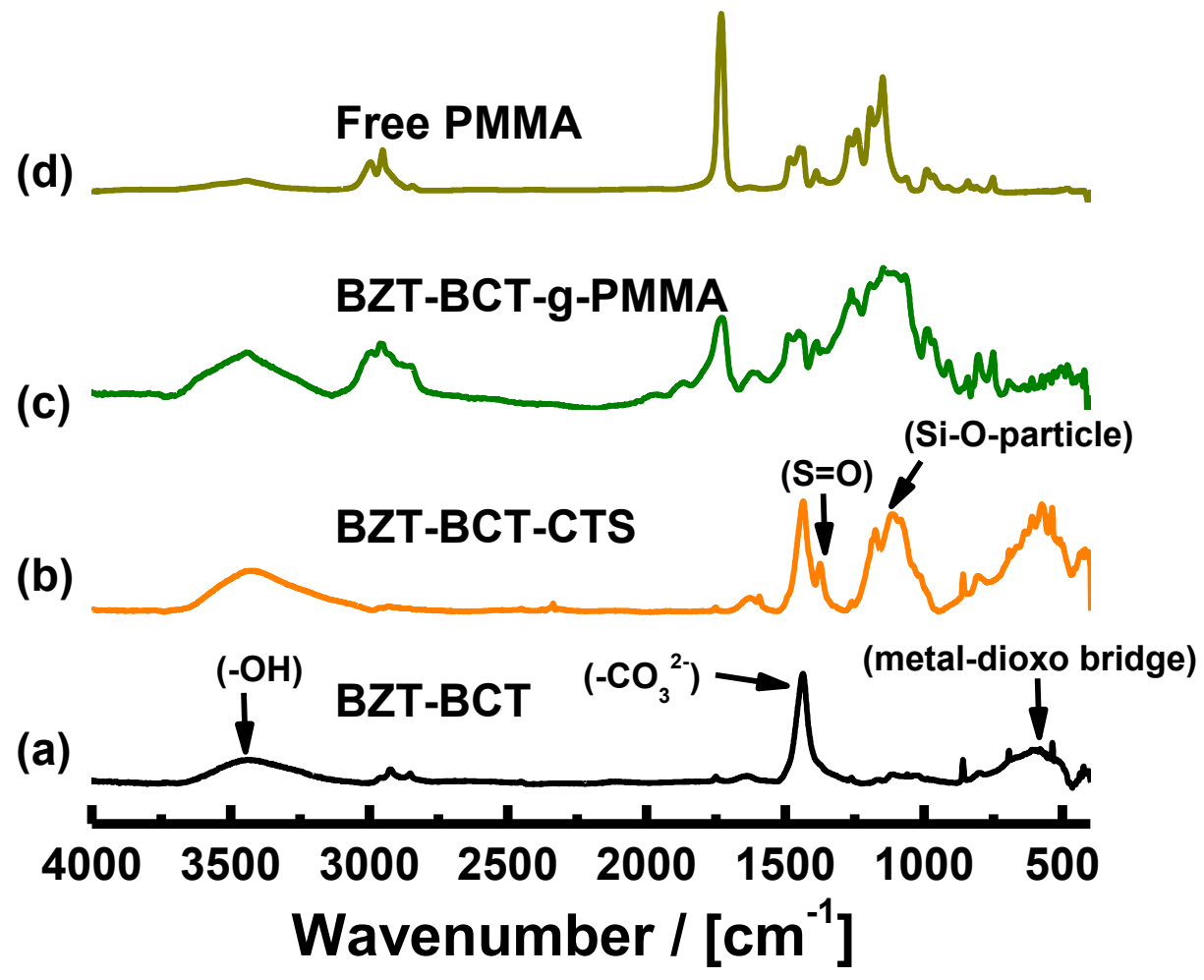


Figure 3

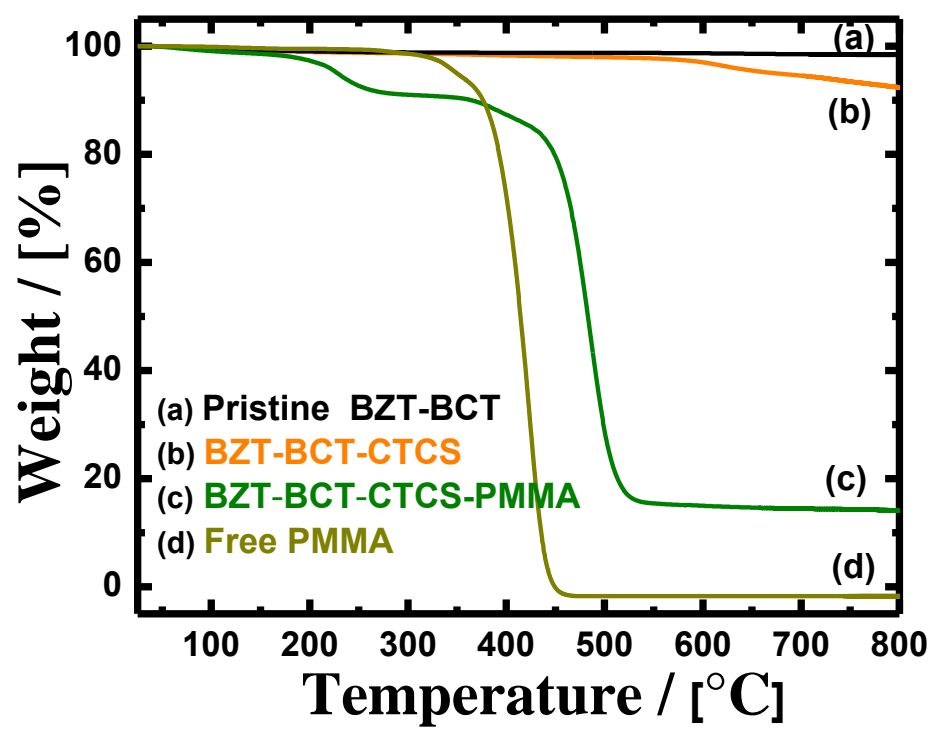


Figure 4
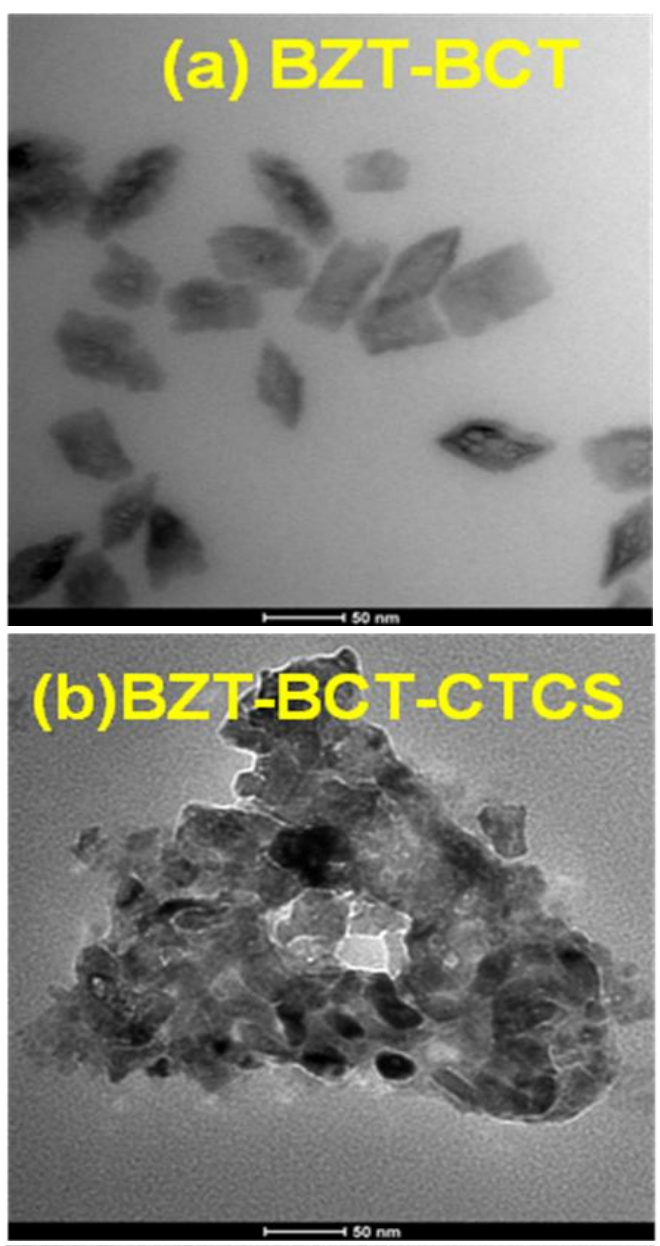

(c)PMMA-g-BZT-BCT

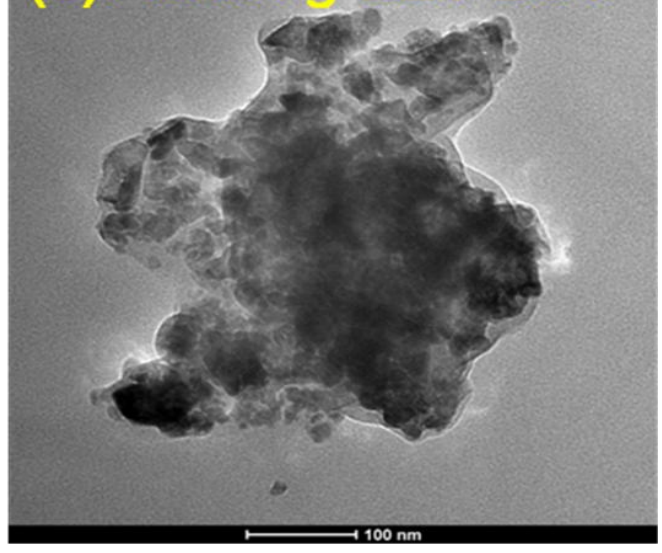


Figure 5
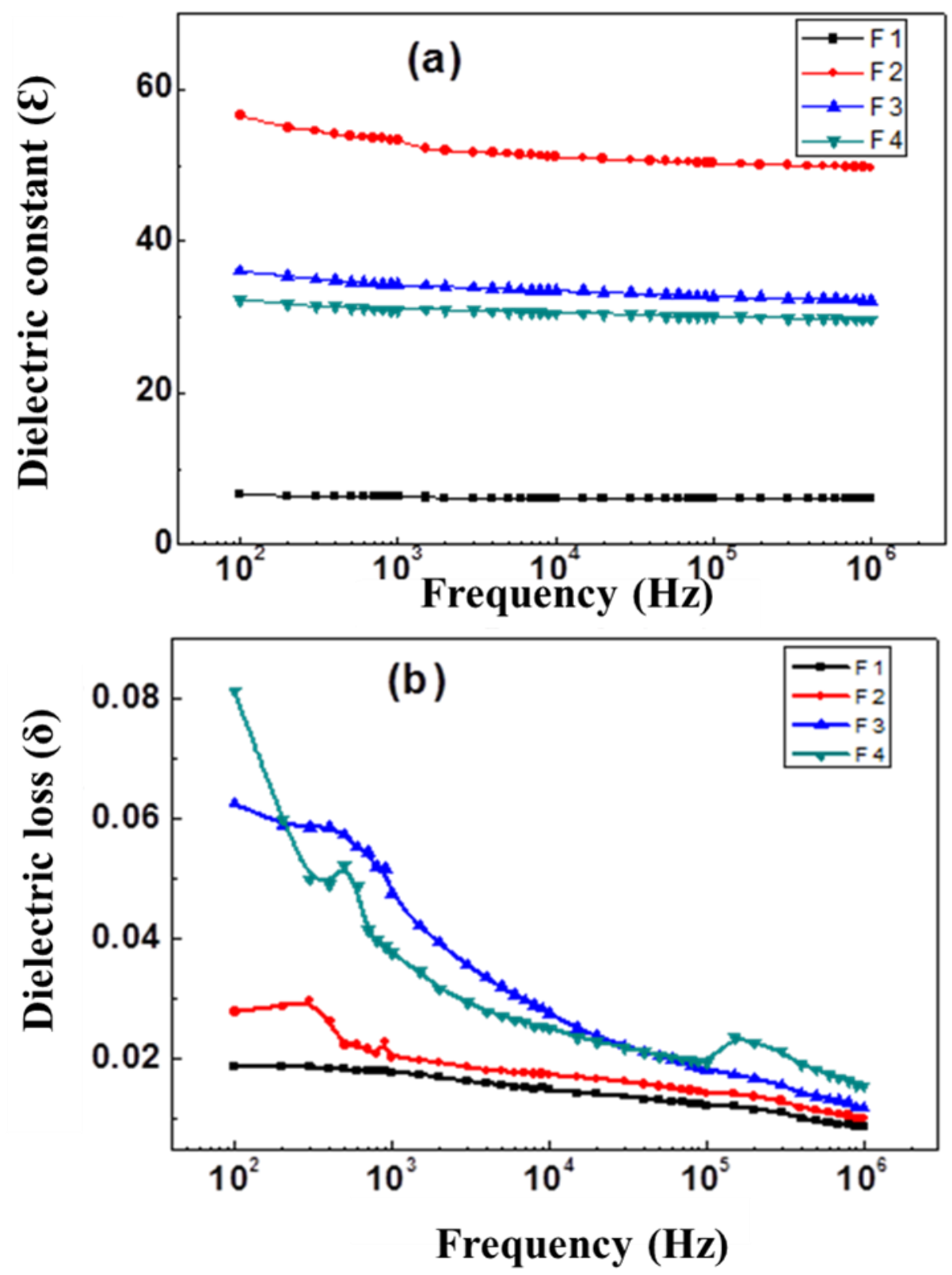
Figure 6

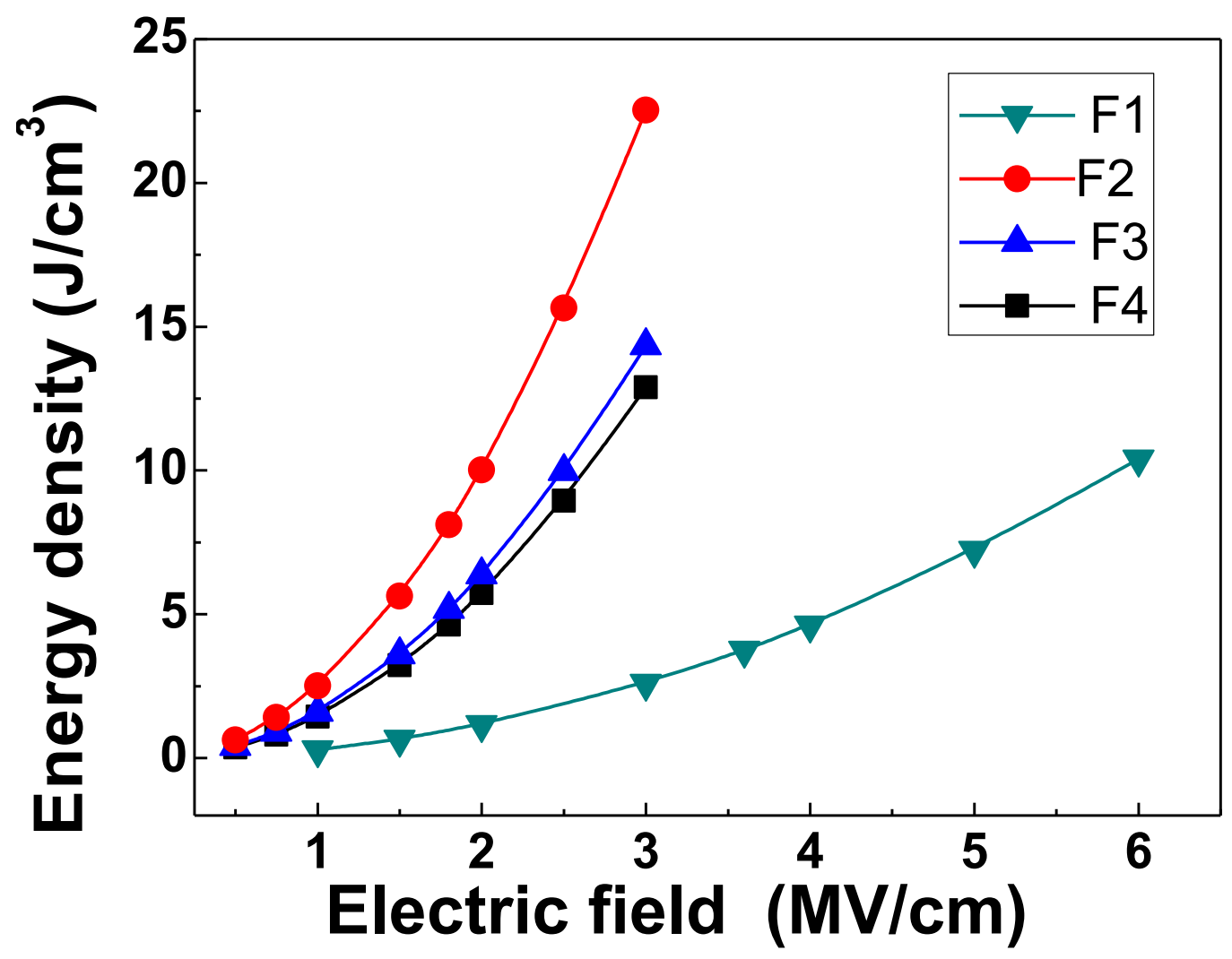


Figure 7

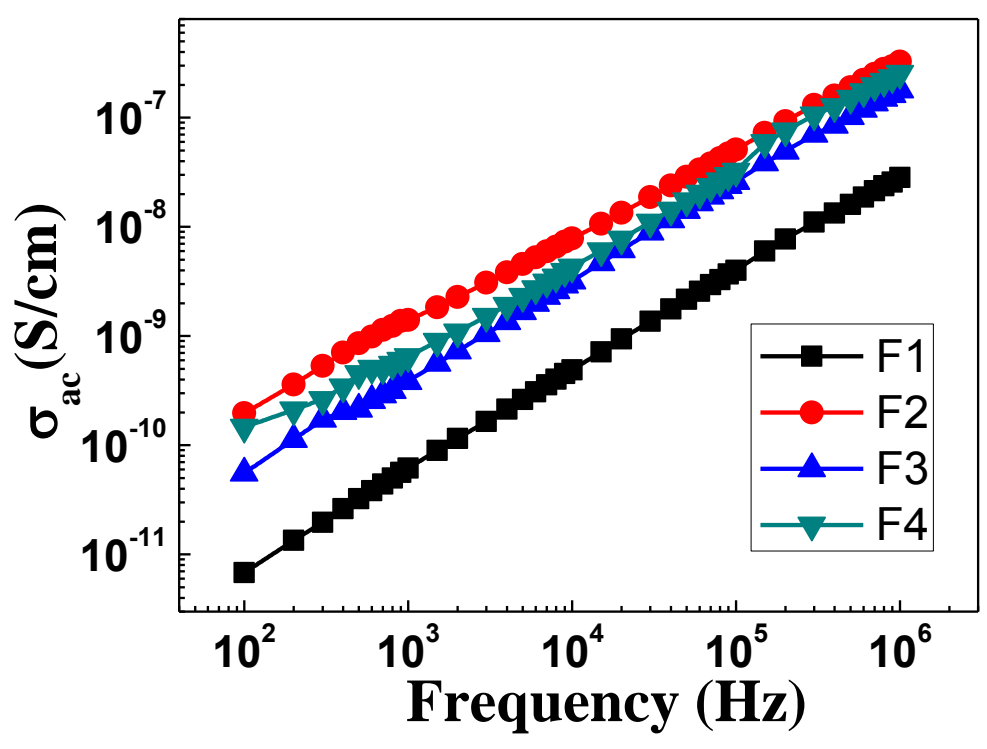




\section{Graphic for Manuscript}

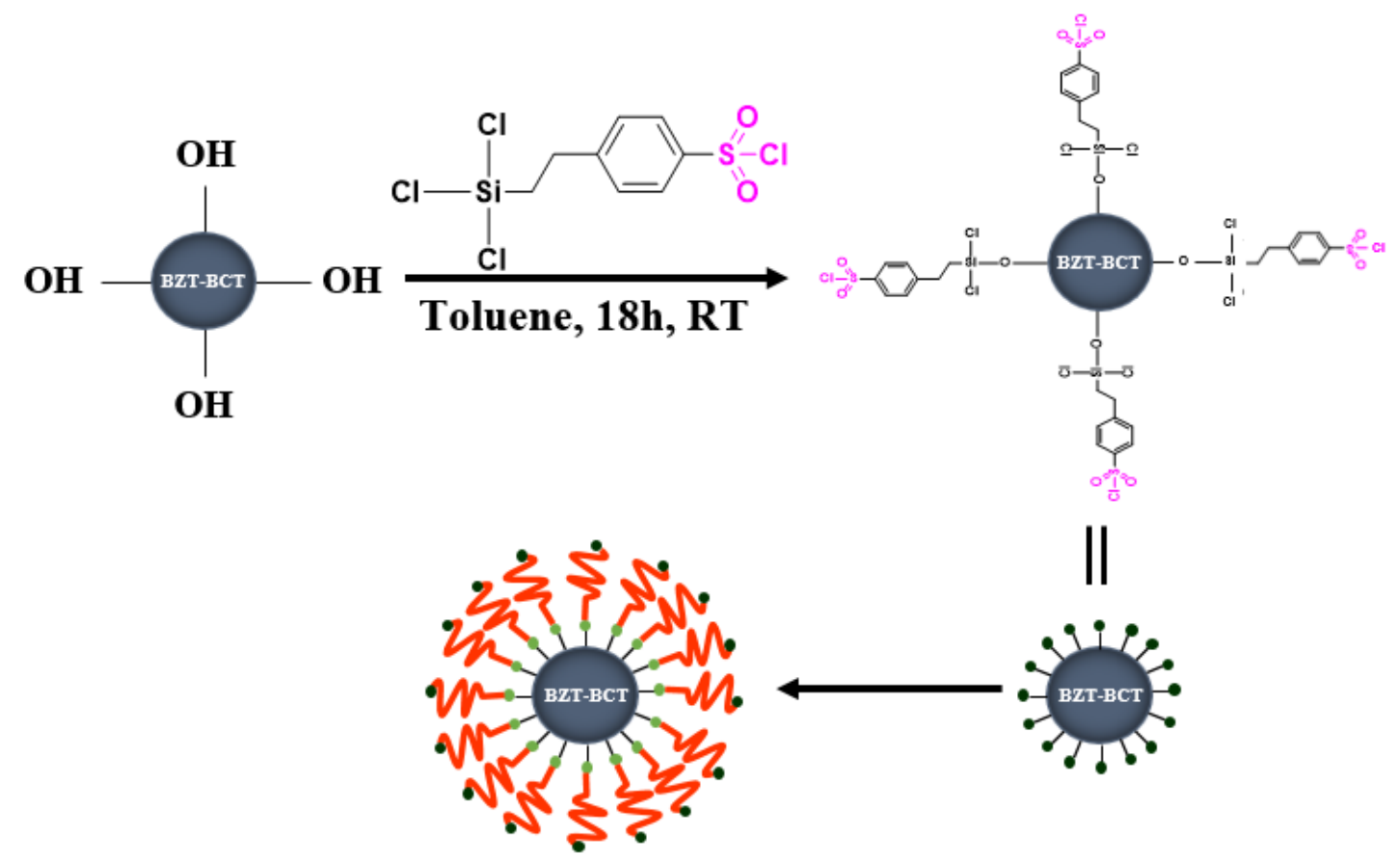

Core-shell structured barium zirconium titanate-barium calcium titanatepoly(methyl methacrylate) $\left[\left(\mathrm{Ba}_{0.94} \mathrm{Ca}_{0.06}\right)\left(\mathrm{Zr}_{0.16} \mathrm{Ti}_{0.84}\right) \mathrm{O}_{3}\right.$-PMMA] nanocomposites were prepared by surface-initiated atom transfer radical polymerization (SI-ATRP) of methyl methacrylate (MMA) from the surface of BZT-BCT nanoparticles. Polymer grafted BZT-BCT nanocomposite thick films $(\sim 10 \mu \mathrm{m})$ have shown an improved dielectric constant $(\varepsilon \sim 56)$, a high breakdown field strength $(\sim 3 \mathrm{MV} / \mathrm{cm})$ and high-energy storage density $\sim 22.5 \mathrm{~J} / \mathrm{cm}^{3}$. The improved electrical properties of core-shell structured BZT-BCT-PMMA nanocomposites were attributed to improved nanoparticle dispersion and enhanced interfacial polarization due to the covalent linkage between polymer and nanoparticle interface. Mechanically stable and homogeneous composite films were obtained using the surface grafted BZTBCT ceramic nanoparticles. 